\title{
Incentive Preferences and Its Related Factors Among Primary Medical Staff in Anhui Province, China: A Cross-Sectional Study
}

Lingzhi Sang

Anhui Medical University

Hongzhang Liu

Anhui Medical University

Huosheng Yan

Anhui Medical University

Jian Rong

Anhui Medical University

Jing Cheng

Anhui Medical University

Li Wang

Anhui Medical University

Hong Ding

Anhui Medical University

Guimei Chen

Anhui Medical University

Ren Chen ( $\nabla$ chenren2006@hotmail.com )

Anhui Medical University https://orcid.org/0000-0003-3626-9450

\section{Research}

Keywords: Primary medical staff, Incentive preference, Exploratory factor analysis, China's Anhui Province

Posted Date: May 11th, 2021

DOl: https://doi.org/10.21203/rs.3.rs-475559/v1

License: (c) (i) This work is licensed under a Creative Commons Attribution 4.0 International License.

Read Full License

Version of Record: A version of this preprint was published at Frontiers in Public Health on January 5th, 2022. See the published version at https://doi.org/10.3389/fpubh.2021.778104. 


\section{Abstract}

Background The shortage of primary medical staff is a major problem in the management of health human resources across all countries. This study focused on the primary medical staff in Anhui Province. By determining their preferences for various motivational and related factors, we examined the correlation between staff's motivation preference levels and staff turnover and turnover intention. This study aimed to further improve the incentive mechanism and to provide a reference for healthcare managers to formulate management strategies for the primary medical staff team.

Methods A self-reported questionnaire survey was conducted to collect data. The basic survey content included demographic characteristics. The absolute level questionnaire and relative level questionnaire on the factors affecting motivation preference were used as the main assessment scales. A total of 1,112 primary-level medical workers in Anhui Province were investigated. T-test, analysis of variance (ANOVA), exploratory factor analysis, and multiple linear regression analysis were performed to analyze the data.

Results The survey respondents (45.1\%) reported being satisfied with their relationship with colleagues, and other social relationships (46.9\%). The Kaiser Meyer Olkin (KMO) value for the absolute preference degree for motivational factors was 0.951 . Two factors (economic and non- economic factors), after using the maximum variance rotation axis method, explained $81.25 \%$ of the total variance. The regression analysis showed that primary medical staff members with high monthly income have a lower preference for non-economic factors; the higher the educational background, the higher their preference for economic factors. In addition, with the increase in participants' age, the preference for motivational factors gradually decreased.

Conclusion Both economic and non-economic factors play an important role in enhancing the enthusiasm of primary medical staff and improving their work attitude. Managers should use their influence to stabilize the primary medical staff.

\section{Background}

Primary-level medical personnel are the basis for ensuring the smooth operation of primary-level medical institutions, and they shoulder the major responsibility of providing basic public health services. This is a universally recognized fact all over the world [1]. Since 2009, when China began to implement a series of new medical system reform measures, the concept of "strengthening primary health services" has been well implemented. Moreover, the purposes of this medical reform in China are to establish and improve the basic medical service system that covers urban and rural residents, and to provide safe, effective, convenient, and affordable medical and health services for all citizens [2]. The improvement of primary medical services has always been the focus of China's health service reform.

Anhui Province is located in the east-central region of China with a moderate level of economic development. Since 2009, Anhui Province has been gradually improving its social medical insurance in primary areas and strengthening primary health care in rural areas [3]. However, Anhui Province has a 
large population, and the distribution of health resources, especially that of human health resources, is still uneven. According to the 2019 statistics, the total population of Anhui Province is 61.955 million, which accounts for $4.43 \%$ of the country's total population. The province has a total of 224,000 health personnel, accounting for only $1.8 \%$ of the country's total; of these, the number primary health personnel in the province is 135,000 , accounting for $3.5 \%$ of the country's total primary health personnel There is also a definite gap in the urban-rural structure: there are 2.01 licensed (assistant) physicians per 1,000 people (2.69 in urban areas and 1.39 in rural areas), 2.37 registered nurses per 1,000 people (3.83 in urban areas and 1.35 in rural areas), and 5.27 health technicians per 1,000 people (7.68 in urban areas and 3.39 in rural areas) [4]. Given the a forementioned problems, some Chinese scholars have proposed that health human resources need to be increased in communities and rural areas to ensure access to public health services for primary residents [5].

The lack of healthcare personnel was brought to light at the beginning of 2020, when countries around the world were hit by the COVID-19 pandemic, and the disease prevention of the primary residents was not guaranteed. This is already becoming a global problem. The quality and density of health human resources are considered important reasons for the dearth of public health services, and this is a widelyrecognized fact globally [6, 7]. The World Health Organization (WHO) emphasizes the chronic shortage of skilled health workers in health systems across countries in their "World Health Report" [1]. In response to this crisis of health human resources, many low- and middle-income countries have widely used community health workers (CHW) to make up for the lack of basic public health services and provide effective health promotion interventions in communities and rural areas [8]. In China, primary health services are generally provided by local primary medical institutions, which include community health service centers, community health service stations, township health centers, village clinics, and outpatient departments. With the promotion of hierarchical diagnosis and treatment, the cooperation between primary medical institutions and large hospitals in big cities has become more sophisticated. However, due to the outdated equipment used in primary medical care, the relatively poor working environment, insufficient salaries, and an inefficient incentive system, primary health institutions are difficult to operate, and primary medical staff are not motivated to work.

Even if primary medical staff provide clinical treatment and public health services at the same time, they usually pay more attention to treatment rather than public health services due to insufficient financial support and incentives to provide these services [9], and the primary medical staff in Anhui Province are no exception to this. In addition to economic incentives, studies in other countries also provide evidence to suggest that the performance of primary medical staff is affected by workload and retention policies [10-12]. Some studies have also shown that basic training and continuing training and education for primary medical staff can improve their performance [13-15]. However, research into primary medical staff in areas with a medium economic level, such as Anhui Province in China, is very limited, which the present study aimed to address.

Work motivation theory and motivation theory posit that when service personnel can expect to achieve their preferred positive outcomes, such as monetary benefits or a sense of accomplishment, for 
completing the tasks demanded by the organization or system, they are better able to work in the direction expected by the health organization or system [16]. Herzberg's two-factor motivational theory also states that the key to improving staff enthusiasm is to invest in motivational factors, because to ensure high-quality medical staff, endogenous motivational factors are more desirable than exogenous motivational factors [17].

Thus, the present study aimed to explore the current status of work motivation and its related factors among primary medical staff in Anhui Province, in order to stabilize the primary medical team, improve the quality of primary medical service, and provide a basis to formulate efficient management strategies for the primary medical team. In turn, providing China's experience of world health human resource management may guide relevant developing countries to formulate their local policy strategies.

\section{Methods}

\section{Studying setting}

According to the latest data from the Chinese Statistics Department, 22,635 primary health institutions in Anhui Province provide outpatient and inpatient services, accounting for $61.27 \%$ and $20.90 \%$ of the total respectively, which are higher than the national averages of $54.12 \%$ and $18.21 \%$, respectively [18]. This province was selected for the following reasons: (1) Anhui has always been at the forefront of China's comprehensive reform of primary medical institutions, making primary medical institutions a priority for the government; (2) Compared with other eastern provinces in China, there are relatively few studies on primary medical staff in Anhui Province; (3) Anhui has several primary medical personnel as shown above. In addition, the study was approved by the Ethical Committee of Anhui Medical University (AMUREC:20170260) and the study team obtained informed consent from all participants. Participants were made aware that they could withdraw at any time.

\section{Participants and data collection}

The primary medical staff in this study refers to medical staff in community health service centers, community health service stations, township health centers, village clinics, and outpatient departments in counties (districts). The surveyed areas included North Anhui, Central Anhui, and Southern Anhui. Random sampling was used to select one county from each city in the three regions. A self-reported questionnaire survey was conducted among the primary medical staff at the selected counties and towns, and participation in the survey was anonymous and voluntary. The questionnaires in each area were collected by special investigators, and completed questionnaires were returned immediately. Before conducting the survey, we provided several training sessions and exercises for the investigators. We also set the following inclusion criteria: (1) participants aged over 20 years; (2) work experience of at least one year; (3) the occupations of the medical staff were limited to doctors, nurses, pharmacists and administrative staff, etc. Before the study was officially initiated, a series of preliminary investigations were also conducted at the same location. 
A total of 1,200 questionnaires were returned, of which 1112 were valid questionnaires, and the effective response rate was $92.67 \%(1112 / 1200)$.

\section{Measures}

After referring to related literature and expert consultation the study included three parts: (1) Participants' general demographic characteristics: gender (male, female), age, professional title (primary, middle, or above), education (secondary school and below, college, bachelor's degree and above), working years (110 years, 11-20 years, 20 years and above), marital status (including married, unmarried); (2) Work characteristics: monthly income (CNY 3000 and below, higher than CNY 3000), occupation (doctor, nurse, pharmacist, and administrative manager), work units (community health service center, community health service station, township health centers, village clinics and outpatient departments); (3) Area: the city and county (district) to which participants belong (according to the geographical characteristics of Anhui Province, the region was divided into northern Anhui, middle Anhui, and southern Anhui).

Based on previous studies and other survey tools related to work motivation [19-21], seven types of motivation factors, including income, working resource conditions, welfare, and career development prospects et al, were included in this study. Accordingly, we independently designed two sets of variables to determine participants' preferences for motivational factors. The first group of variables was ranked by participants' preference levels based on their satisfaction with these variables. The responses were ranked into five levels, ranging from 1 ("very dissatisfied") to 5 ("very satisfied"). For the second group of variables, to measure the absolute level of participants' preferences for each motivational factor, a 5-point Likert scale was used to assess the motivational factors that increase participants' effort. It should be noted that the motivational factors in this scale are divided into 11 categories. For each type of motivational factor, the following question was asked: "If the salary level (reward method/benefits/...) improves, how much will your work effort increase?". The responses were made on a scale ranging from 1 ("no improvement") to 5 ("considerable improvement"). In addition, basic information on participants was obtained: gender, age, educational background, working years, marital status, average monthly income, job position, and type of primary medical institution. As quality control personnel, undergraduates and graduate students majoring in preventive medicine and health management explained the questionnaires at the survey site, and collected and checked the questionnaires. It is worth mentioning that all research assistants were trained in data collection..

\section{Statistical analyses}

We used SPSS 24.0 for data analysis, and the mean and composition ratio were used to describe participants' degree of preferences for various motivational factors. T-test and analysis of variance (ANOVA) were used to perform a single-factor analysis of the incentives of binary variables (gender, marital status, monthly income). Then, we divided the age of primary medical staff into four groups: $\leq 35$ years, $36-45$ years, and $>45$ years; thus, the age of primary medical staff was transformed from a continuous variable to a categorical variable. One-way ANOVA was performed for multiple categorical variables (including age, education, institution, occupation, and region). If there was no homogeneity of 
variance, the Kruskal-Wallis $\mathrm{H}$ test was performed. We also constructed a multiple linear regression model to analyze the differences in the degree of participants' preference for motivation factors under different conditions $(a=0.05)$.

The exploratory factor analysis method was used to analyze the inner level of the participants' demand for motivating factors, mainly to extract the latent factors among the included variables. First, we measured the KMO value of the selected scale and checked whether the p-value is less than 0.0001 using the Bartlett sphere method, which then determined whether this set of variables is suitable for factor analysis. Second, we use the principal component method to extract two factors, which would explain the variance in all variables. The maximum variance rotation axis method was used to orthogonally rotate the factor load matrix, to obtain the rotated factor load matrix. Finally, variables with load values $>0.5$ were attributed to a common factor, and they were labelled "non-economic factors" and "economic factors." At the same time, the reliability and validity of the scale were also evaluated.

\section{Results}

\section{Socio-demographic characteristics of participants}

A total of 1112 participants were studied, of whom 609 were women and 503 were men, accounting for $54.8 \%$ and $45.2 \%$ of the participants, respectively. The participants were $36-45$ years old, with an average age of $(40.22 \pm 8.453)$. There were 482 people with a high school education or less, accounting for $43.3 \%$ of the total, and 545 medical staff with a monthly income of 2000-3000, accounting for 49.0 $\%$ of the total. Among different occupations, there were 579 doctors $(52.1 \%)$ and 235 nurses $(21.1 \%)$. 
Table 1

Socio-demographic characteristics of participants $(n=1112)$

\begin{tabular}{|c|c|c|}
\hline Demographic variable & Number of people (n) & Composition ratio (\%) \\
\hline \multicolumn{3}{|l|}{ Gender } \\
\hline Male & 503 & 45.2 \\
\hline Female & 609 & 54.8 \\
\hline \multicolumn{3}{|l|}{ Age (years) } \\
\hline$<36$ & 296 & 26.6 \\
\hline $36 \varangle 45$ & 502 & 45.1 \\
\hline$>45$ & 314 & 28.2 \\
\hline \multicolumn{3}{|l|}{ Education level } \\
\hline secondary school and below & 482 & 43.3 \\
\hline Associate degree & 435 & 39.1 \\
\hline Bachelor degree and above & 195 & 17.5 \\
\hline \multicolumn{3}{|l|}{ Marital status } \\
\hline Married & 1017 & 91.5 \\
\hline Unmarried & 95 & 8.5 \\
\hline \multicolumn{3}{|l|}{ Monthly income (CNY) } \\
\hline $2000 \rrbracket 3000$ & 545 & 49.0 \\
\hline $3001 \rrbracket 4000$ & 347 & 31.2 \\
\hline$\geq 4000$ & 220 & 19.8 \\
\hline \multicolumn{3}{|l|}{ Occupation } \\
\hline Physicians & 579 & 52.1 \\
\hline Pharmacists & 235 & 21.1 \\
\hline Nurses & 298 & 26.8 \\
\hline \multicolumn{3}{|l|}{ Regions } \\
\hline North of Anhui & 770 & 69.2 \\
\hline Middle of Anhui & 209 & 18.8 \\
\hline South of Anhui & 133 & 12.0 \\
\hline
\end{tabular}




\begin{tabular}{|lcc|}
\hline Demographic variable & Number of people (n) & Composition ratio (\%) \\
\hline Work units & & \\
CHC & 171 & 15.4 \\
CHS & 688 & 61.9 \\
\hline Township hospitals & 171 & 15.4 \\
Village clinics & 82 & 7.4 \\
\hline CHC, community health service center CHS, community health service station \\
\hline
\end{tabular}
Description Of the relative level of motivation factor
preference and satisfaction

Primary medical staff members were found to be highly satisfied with the three motivational factors of colleague relations, social relations, and management styles. While 502 people (45.1\%) were quite satisfied, 219 people $(19.7 \%)$ were very satisfied with the relationship between colleagues. Moreover, 522 people ( $46.9 \%$ ) were relatively satisfied with social relationships; 483 people (43.4\%) were relatively satisfied with management methods; 194 people $(17.4 \%)$ were not very satisfied with their sense of pride and accomplishment; 262 people $(20.3 \%)$ were not very satisfied with welfare and security; and 387 people $(34.8 \%)$ were not very satisfied with their income. 
Table 2

Description of the relative level of motivation factor preference and satisfaction

\begin{tabular}{|c|c|c|c|c|c|c|c|c|c|c|c|}
\hline \multirow[t]{2}{*}{ Motivating factor } & \multirow[t]{2}{*}{$\begin{array}{l}M \pm \\
S D\end{array}$} & \multicolumn{2}{|c|}{$\begin{array}{l}\text { Very } \\
\text { dissatisfied }\end{array}$} & \multicolumn{2}{|c|}{$\begin{array}{l}\text { Not so } \\
\text { satisfied }\end{array}$} & \multicolumn{2}{|c|}{$\begin{array}{l}\text { Generally } \\
\text { satisfied }\end{array}$} & \multicolumn{2}{|c|}{$\begin{array}{l}\text { Relatively } \\
\text { satisfied }\end{array}$} & \multicolumn{2}{|c|}{$\begin{array}{l}\text { Very } \\
\text { satisfied }\end{array}$} \\
\hline & & n & $\%$ & n & $\%$ & n & $\%$ & n & $\%$ & n & $\%$ \\
\hline $\begin{array}{l}\text { Colleague } \\
\text { relations }\end{array}$ & $\begin{array}{l}3.78 \\
+ \\
0.84\end{array}$ & 13 & 1.2 & 43 & 3.9 & 335 & 30.1 & 502 & 45.1 & 219 & 19.7 \\
\hline $\begin{array}{l}\text { Social } \\
\text { relationship }\end{array}$ & $\begin{array}{l}3.46 \\
+ \\
0.82\end{array}$ & 13 & 1.2 & 78 & 7.0 & 522 & 46.9 & 380 & 34.2 & 119 & 10.7 \\
\hline $\begin{array}{l}\text { Management } \\
\text { method }\end{array}$ & $\begin{array}{l}3.17 \\
+ \\
0.97\end{array}$ & 55 & 4.9 & 186 & 16.7 & 483 & 43.4 & 294 & 26.4 & 94 & 8.5 \\
\hline $\begin{array}{l}\text { Pride and } \\
\text { accomplishment }\end{array}$ & $\begin{array}{l}3.05 \\
+ \\
0.97\end{array}$ & 73 & 6.6 & 194 & 17.4 & 532 & 47.8 & 232 & 20.9 & 81 & 7.3 \\
\hline $\begin{array}{l}\text { Working resource } \\
\text { conditions }\end{array}$ & $\begin{array}{l}2.90 \\
+ \\
0.97\end{array}$ & 89 & 8.0 & 262 & 23.6 & 480 & 43.2 & 228 & 20.5 & 53 & 4.8 \\
\hline $\begin{array}{l}\text { Welfare } \\
\text { guarantee }\end{array}$ & $\begin{array}{l}2.54 \\
+ \\
1.07\end{array}$ & 226 & 20.3 & 291 & 26.2 & 395 & 35.5 & 164 & 14.7 & 36 & 3.2 \\
\hline Income & $\begin{array}{l}2.48 \\
+ \\
0.97\end{array}$ & 186 & 16.7 & 387 & 34.8 & 387 & 34.8 & 127 & 11.4 & 25 & 2.2 \\
\hline
\end{tabular}

\section{Exploratory factor analysis on the levels of various motivational factors}

We used exploratory factor analysis to extract the potential factors from the preference variables of motivational factors; through the interpretation of the meaning of these factors, the level of motivational factor needs of primary medical staff were found. The KMO value of the measure of absolute preference degree of motivational factors was 0.95 , and the result of Bartlett's sphere test was statistically significant at $P<0.0001$, indicating that this set of variables is suitable for further factor analysis.

First, two value factors were extracted by the principal component method, and then the axis of maximum variance method was used. The rotated factor loading matrix was obtained after its orthogonal rotation. The test results showed that two factors can explain $81.25 \%$ of the variance of all variables. Second, we attributed variables with load values $>0.5$ to a common factor, and then named them as non-economic factor and economic factor preferences based on the content reflected by the explanatory variables of each factor. Finally, the internal consistency coefficient of the corresponding original variable explained by each factor showed that the internal consistency of the variable is 
acceptable. The Cronbach's a value was 0.94 . The preference of primary medical staff in Anhui Province for economic factors was determined to be higher than that for non-economic factors; this result was obtained from the average results of various incentive factors.

Table 3

Exploratory factor analysis on the levels of various motivational factors

\begin{tabular}{|lll|}
\hline Factors & Factor extraction & \\
\cline { 2 - 3 } & $\begin{array}{l}\text { Non-economic factors } \\
(\text { F1) }\end{array}$ & $\begin{array}{c}\text { Economic factors } \\
\text { (F2) }\end{array}$ \\
\hline Salary level & 0.336 & 0.857 \\
\hline Reward method & 0.387 & 0.841 \\
\hline Welfare & 0.416 & 0.829 \\
\hline Guarantee mechanism & 0.433 & 0.809 \\
\hline Working environment & 0.728 & 0.498 \\
\hline Medical equipment & 0.749 & 0.426 \\
\hline Management method & 0.797 & 0.386 \\
\hline Colleague relations & 0.828 & 0.318 \\
\hline Sense of pride and accomplishment & 0.804 & 0.383 \\
\hline Social relationship & 0.845 & 0.343 \\
\hline $\begin{array}{l}\text { Cumulative variance contribution rate after } \\
\text { rotation(\%) }\end{array}$ & 43.96 & 81.25 \\
\hline Internal consistency coefficient & 0.94 & 0.94 \\
\hline Means of each motivation factor & 3.57 & 3.62 \\
\hline Multiple linear regression analysis On the preference degree \\
\hline Of Various motivational factors and related factors
\end{tabular}

The univariate analysis results showed that there was a statistically significant difference between noneconomic factors based on gender $(t=-1.515, P=0.1300)$, age $(F=7.33, P=0.001)$, monthly income $(F=$ $3.86, p=0.021)$, and occupation $(F=6.91, p=0.001)$; as well as between economic factors based on gender $(t=-2.22, p=0.026)$, age $(F=4.46, p=0.01)$, educational background $(F=4.65, p=0.01)$, and work unit $(F=2.08, p<0.01)$.. The Kruskal-Wallis $H$ test method was used for the two factors that had an uneven variance: occupation $\left(\chi^{2}=5.541, p=0.063\right)$ and region $\left(x^{2}=3.774, p=0.151\right)$. Then, we took noneconomic factors and economic factors as dependent variables, and included statistically significant factors such as gender, age, educational background, monthly income, job position, region, and work unit, as independent variables in a single factor analysis. A multiple linear regression analysis was performed, 
and the results showed that the monthly income of primary medical staff was negatively correlated with the preference degree of non-economic factors. Similarly, age and the preference degree of economic factors were also negatively correlated. However, academic qualifications were positively correlated with the degree of preference for economic factors, that is, the higher the degree of education, the higher the individual's preference for economic factors.

Table 4

Multiple linear regression analysis on the preference degree of various motivation factors and related factors

\begin{tabular}{|lllllll|}
\hline Factors & Independent variable & $\boldsymbol{\beta}$ & $\mathbf{S}_{\mathbf{X}}$ & $\boldsymbol{\beta}^{\prime}$ & $\boldsymbol{t}$ & $\boldsymbol{P}$-value \\
\hline Non-economic factors & Constant terms & 0.221 & 0.167 & & 1.320 & 0.187 \\
& Age(years) & -0.150 & 0.065 & -0.111 & -2.302 & $0.022^{*}$ \\
\hline Economic factors & Monthly income & -0.094 & 0.039 & -0.073 & -2.420 & $0.016^{*}$ \\
& Constant terms & -0.210 & 0.233 & & -0.904 & 0.366 \\
\hline Age(years) & -0.156 & 0.066 & -0.116 & -2.383 & $0.017^{*}$ \\
\hline * P-value $<0.05$ & Education & 0.088 & 0.043 & 0.065 & 2.039 & $0.042^{*}$ \\
\hline
\end{tabular}

\section{Discussion}

\section{Research on economic incentives}

The results of this study showed that at present, welfare and income are the two motivational factors with which primary medical staff in Anhui are the most dissatisfied. This also shows that their expectations for material rewards are often high, which fits the results of the exploratory factor analysis. In other words, when comparing averages of the various incentive factors, the preference of basic-level medical staff for economic factors is higher than that for non-economic factors. This result is consistent with the results of a study in China [20], in which primary medical staff was found to value material incentives over non-material incentives. At the same time, a cross-sectional survey on the job satisfaction of primary medical staff in Shandong Province, China [21] also pointed out that the most dissatisfactory aspect of primary-level health workers is their salary. In addition, two Chinese studies [22, 23] pointed out that health workers have a strong demand for higher wages and benefits. This situation is more common in primary medical institutions, and has been a long-standing problem. However, a study in Lithuania [24] showed that most primary doctors accepted their current working conditions, and correspondingly, their job satisfaction was high. The reason for this difference could be the different healthcare conditions between the two countries: Lithuania is in southern Europe with a small population and a small area, so it is convenient for the distribution of health human resources, especially when it comes to the distribution of these resources in communities and villages. Moreover, the country has a high degree of medical 
specialization; hence, it is convenient to carry out medical training for general practitioners. However, China has a large area with a large population, and the unfair distribution of health resources among regions is inevitable. Faced with limited health resources, it is difficult for medical services to be easily accessible to communities and in rural areas.

A previous job satisfaction survey of general practitioners in Hubei Province found that young doctors may leave their jobs because of low job satisfaction [25], which fits well with the conclusion of this study, i.e., age and material incentive preference is negatively correlated. It is reasonable that young doctors tend to value material incentives more than older doctors. As young people, they are inferior to older doctors in wealth and social status, which encourages these young people to work harder, such that the level of their salary often becomes an important indicator of their progress.

As for Anhui Province, the reasons for the low satisfaction of primary medical staff may be many. First, due to limited health human resources, the workload of primary medical staff is often larger than that of other medical staff, so overtime is more common. Second, the subsidy systems of medical institutions are imperfect, and overtime subsidies cannot be paid on time, such that the input and return of the workload of the staff ends up being disproportionate [26]. The basic public health subsidies for rural doctors are in place [27], which leads to the dissatisfaction of basic-level medical staff with remuneration.

Therefore, it is particularly important and even urgent to establish a scientific and reasonable salary and incentive system. China has begun to implement a reform of the medical insurance payment method, and the "pay by individual" method has begun to take effect. This payment method can transform the increased investment in health into an improvement in the income and welfare of medical staff [28]. At the same time, it not only pays attention to the salary of workers, but also pays attention to the fairness and reasonableness of the distribution process [29]. China's health department should consider giving this system greater operational and personnel autonomy to stimulate its innovative vitality [30, 31].

\section{Research on non-economic incentives}

The results of this study found that primary medical staff in Anhui Province valued economic factors more than non-economic factors, but the difference between the two was not big, which shows that noneconomic incentives also have a positive effect on workers. Previous studies have shown that the incentive effects of non-economic factors include the improvement of the work environment and an enhanced sense of work accomplishment [32]. A survey of rural doctors in China showed that the economic returns of primary care in primary areas are much lower than that of high-level hospitals in cities [33]. The core of the problem faced by primary medical staff is salary inequality; this is because the generation of income depends largely on higher service fees and paper publishing income [34]. A satisfaction survey of community health workers also showed that the salary of primary medical staff is relatively lower than that of medical staff in higher-level hospitals in cities, and it is difficult for these primary health workers to get a big increase in their income in a short period of time. In summary, the noneconomic incentives of the primary medical staff need to be strengthened. Some scholars believe that 
good colleague relations and the support of superior leaders will bring job satisfaction [35]. A research report on health workers in dozens of low and middle-income countries around the world suggested that fair treatment and mutual respect among colleagues, supervisors, organizations, and patients will also affect intrinsic motivation and enthusiasm [36]. Anhui Province is an area with a medium economic level and a large proportion of its population in primary areas. In terms of the management strategy of primary health workers, good non-economic incentives have an important impact on improving their motivation to work, which undoubtedly fits the current situation in Anhui Province.

In this regard, we recommend that health departments take active and effective action to provide noneconomic incentives to primary medical staff, such as improving their working environment. A study in Ghana, which is a developing country, found that poor working environment and limited job prospects are the prominent negative factors experienced by primary health workers [37]. Systematic research on the motivation and retention of health workers in developing countries by the scholars of the World Health Organization determined that adequate supply and proper infrastructure are two factors that can significantly improve morale and increase employee motivation [38]. It is time to bring in these experiences and apply them to some developing regions in China.

\section{Analysis of the reasons for the influence of different motivational factors}

It is worth mentioning that the multi-factor analysis of the level of incentive preference shows that primary medical staff members with low monthly income have a higher preference for non-economic factors. We speculate that incentives relating to non-economic factors may be at work in increasing the workers' sense of accomplishment about their work, such as, in the case of an improvement in social relations at the workplace. Health workers with higher educational backgrounds have a higher preference for economic factors. It may be that they have received higher medical education and training, and their corresponding training costs were higher than those of other health workers. Therefore, they place higher expectations on salary and benefits. However, once their actual economic income differs too much from the expected value, they may tend to feel that their effort and income cannot match [39], which arouses their dissatisfaction. In addition, the differences in incentive preferences between medical staff due to differences in their ages are not consistent with the results of a study of community general practitioners [16]; the reason may be that the subjects of our study were rural health workers. Compared with general practitioners, the working environment of rural health workers is worse, and capital investment and operation are more difficult.

\section{Limitations}

Although we conducted a lot of quality control before the field survey and data analysis, we must admit that this study still has some limitations. First, the sample is only part of the primary medical staff in Anhui Province; hence, their overall situation may not be able to describe all Chinese health staff. Secondly, the sample includes participants mainly from Anhui Province in central China, while participants from other provinces in China (especially developing regions) were not included; hence, 
further comparative analysis cannot be performed effectively. Finally, some potential confounding factors are inevitable, such as the facilities of medical institutions and traditional ideas.

\section{Conclusions}

This study investigated the incentive preference level of primary medical staff in Anhui Province, and we also found some related factors that affect their incentive preference. The results show that the monthly income, education, and age of health workers may affect their incentive preferences. For young people with a low monthly income and high educational level, sufficient attention should be paid to their current life and work status. This was the key population of this study. In addition, managers should combine economic incentives with non-economic incentives; adapt measures to local conditions and individual preferences, which may vary; refer to the experience of domestic and foreign research to improve the welfare system of primary medical staff and increase their job satisfaction; and gradually increase their income. At the same time, enhancing the enthusiasm and self-confidence of the staff in their current work and creating an optimistic working atmosphere must also be looked into.

\section{Abbreviations}

ANOVA: analysis of variance; WHO: World Health Organization; $\mathrm{CHC}$ : community health service centers; CHS: community health service stations; SD: Standard Deviation; M: means

\section{Declarations}

\section{Supplementary information}

Additional file: Questionnaire for this study

\section{Acknowledgements}

We would like to thank Editage (www.editage.cn) for English language editing.

\section{Authors' contributions}

LZ S participated in the survey, the data analysis and the writing of the article. $\mathrm{HZ} L$ took part in the design of the study and the writing of the article. JR and HS Y contributed to the data collection and screening. CJ, LW and HD were involved in the data analysis and participated in the literature research. $\mathrm{RC}$ and GM C made a second revision of the manuscript. All authors have read and approved the final version.

\section{Funding}

This work was supported by Major Project of Humanities and Social Sciences Research in Anhui Higher Education Institutions (grant numbers: SK2017A0169) and the National Nature Science Foundation of 
China (grant numbers:71874002, 71303007 and NSFC71704003). The sponsors and funding agencies had no role in design and implementation of this study or the preparation of this article.

\section{Availability of data and materials}

All data generated or analyzed during this study is included in the article published here and its supplementary information files.

\section{Ethics approval and consent to participate}

The study was approved by the Ethical Committee of Anhui Medical University (AMUREC:20170260) and the study team obtained informed consent from all participants. Participants were made aware that they could withdraw at any time.

\section{Consent for publication}

Not applicable

\section{Competing interests}

The authors declare that they have no competing interests.

\section{Author details}

${ }^{1}$ School of Health management, Anhui Medical University, No. 81, Meishan Road Shushan District, Hefei 230032, Anhui, China.

\section{References}

1. WHO. The world health report: 2006: working together for health. http://apps.who.int/iris/handle/10665/43432. [Accessed on Jan 8 2017].

2. Yip W, Hsiao W. Harnessing the privatization of China's fragmented health-care delivery. Lancet. 2014;384(9945):805-18.

3. Li L, Fu H. China's health care system reform: Progress and prospects. Int J Health Plann Manage. 2017;32(3):240-53.

4. National Health and Family Planning Commission of the People's Republic of China. Statistical yearbook of China's health and family planning. Beijing. China: Peking Union Medical College Press; 2019.

5. Zhou P, Yang XL, Wang XG, et al. A pneumonia outbreak associated with a new coronavirus of probable bat origin. Nature. 2020;579(7798):270-3.

6. Anand S, Fan VY, Zhang J, et al. China's human resources for health: quantity, quality and distribution. Lancet. 2008;372(9651):1774-81. 
7. Anand S, Bärnighausen T. Human resources and health outcomes: cross-country econometric study. Lancet. 2004;364(9445):1603-9.

8. Chen L, Evans T, Anand S, et al. Human resources for health: overcoming the crisis. Lancet. 2004;364(9449):1984-90.

9. McConnell J. Barefoot no more. Lancet. 1993 May;15(8855):1275. 341(.

10. Campbell C, Scott K. Retreat from Alma Ata? The WHO's report on task shifting to community health workers for AIDS care in poor countries. Glob Public Health. 2011;6(2):125-38.

11. Jaskiewicz W, Tulenko K. Increasing community health worker productivity and effectiveness: a review of the influence of the work environment. Hum Resour Health. 2012;10(1):1.

12. Mohajer N, Singh D. Factors enabling community health workers and volunteers to overcome sociocultural barriers to behaviour change: meta-synthesis using the concept of social capital. Hum Resour Health. 2018;16(1):63.

13. Bhutta ZA, Lassi ZS, Pariyo G, Huicho L. Global experience of community health workers for delivery of health-related millennium development goals: a systematic review, country case studies and recommendations for integration into national health systems. Glob Health Workforce Alliance. 2010;1:249-61.

14. Hermann K, Van Damme W, Pariyo GW, et al. Community health workers for ART in sub-Saharan Africa: learning from experience-capitalizing on new opportunities. Hum Resour Health. 2009;7:31.

15. Palazuelos D, Ellis K, Im DD, et al. 5-SPICE: the application of an original framework for community health worker program design, quality improvement and research agenda setting. Glob Health Action. 2013;6:19658.

16. KanferR. Measuring health worker motivation in developing countries[R]. Major Applied Research 5, Working Paper 1. Partnership for Health Reform Project, Bethesda, Maryland:1999.

17. Herzberg F. Work and the nature of man. New York: World Publishing; 1966.

18. National health commission of the People's Republic of China. Yearbook of Health in the People's Republic of China 2018. Beijing: Peking Union Medical College Press; 2018.

19. Paleologou V, Kontodimopoulos N, Stamouli A, et al. Developing and testing an instrument for identifying performance incentives in the Greek health care sector. BMC Health Serv Res. 2006;6:118.

20. Yuan BB, Meng QY, Song KM, et al. Preference for working motivation and its influencing factors among rural health workers. Chinese Journal of Public Health. 2012;28(11):1407-10.

21. Gu J, Zhen T, Song Y, et al. Job satisfaction of certified primary care physicians in rural Shandong Province, China: a cross-sectional study. BMC Health Serv Res. 2019;19(1):75.

22. Liu J, Zhu B, Wu J, et al. Job satisfaction, work stress, and turnover intentions among rural health workers: a cross-sectional study in 11 western provinces of China. BMC Fam Pract. 2019;20(1):9.

23. Zhao DJ, Chen JY, Chen MS, et al. Research on the status quo of primary health human resources in rural areas of northern Jiangsu. Journal of community medicine. 2016(7):38-40. 
24. Buciuniene I, Blazeviciene A, Bliudziute E. Health care reform and job satisfaction of primary health care physicians in Lithuania. BMC Fam Pract. 2005;6(1):10.

25. Gan $Y$, Gong $Y$, Chen $Y$, et al. Turnover intention and related factors among general practitioners in Hubei, China: a cross-sectional study. BMC Fam Pract. 2018;19(1):74.

26. Huang L, Guo XM, Zhou YY. The Satisfaction Status of Rural Health Human Resource in Rural Medical Institutions in Sichuan Province. Chinese Health Quality Management. 2018;25(2):124-7.

27. Jia HY. Research on the evaluation and strategy development of rural doctors in Shandong Province under the background of new medical reform [master dissertation] Weifang, China: Weifang Medical College, 2016.

28. He P, Zhao XJ, Liu B, et al. Status quo and determinants on job satisfaction of rural primary care providers in Anhui province. Chinese Health Resources,2014,17(1):60-63.

29. Wang H, Chen H, Chen JM, et al. Correlation Study on Payment Satisfaction, Psychological Reward Satisfaction and Turnover Intention of Nurses. Chinese Hospital Management. 2018;38(3):64-6.

30. Akroyd D, Wilson S, Painter J, et al. Intrinsic and extrinsic predictors of work satisfaction in ambulatory care and hospital settings. J Allied Health. 1994;23(3):155-164. 1994;23(3):155.

31. Dowell AC, Hamilton S, McLeod DK. Job satisfaction, psychological morbidity and job stress among New Zealand general practitioners. N Z Med J. 2000;113(1113):269-72.

32. Powell-Jackson T, Yip WC, Han W. Realigning demand and supply side incentives to improve primary health care seeking in rural China. Health Econ. 2015;24(6):755-72.

33. Zhang $S$, Zhang W, Zhou H, et al. How China's new health reform influences village doctors' income structure: evidence from a qualitative study in six counties in China. Hum Resour Health. 2015;5:1326.

34. Millar R, Chen $\mathrm{Y}$, Wang $\mathrm{M}$, et al. It's all about the money? A qualitative study of healthcare worker motivation in urban China. Int J Equity Health. 2017;16(1):120.

35. Ge C, Fu J, Chang Y, Wang L. Factors associated with job satisfaction among Chinese community health workers: a cross-sectional study. BMC Public Health. 2011;11:884.

36. Okello DR, Gilson L. Exploring the influence of trust relationships on motivation in the health sector: a systematic review. Hum Resour Health. 2015;13:16.

37. Alhassan RK, Nketiah-Amponsah E. Frontline staff motivation levels and health care quality in rural and urban primary health facilities: a baseline study in the Greater Accra and Western regions of Ghana. Health Econ Rev. 2016;6(1):39.

38. Willis-Shattuck M, Bidwell $P$, Thomas $S$, et al. Motivation and retention of health workers in developing countries: a systematic review. BMC Health Serv Res. 2008;8:247.

39. Chen DD, Chen XD. A meta-study of literature on medical staff salary satisfaction. Health Economics Research. 2011(9):42-45.

\section{Supplementary Files}


This is a list of supplementary files associated with this preprint. Click to download.

- AdditionalfileSurveyquestionnairesforthisstudy.docx 